\title{
Emotional Intelligence, Learning Motivation and Inclusion Ability among Arab Minority Special Education Teachers in Israel
}

\author{
Waleed Dallasheh ${ }^{1}$, Ihab Zubeidat ${ }^{2, *}$, Sehrab Masri ${ }^{3}$ \\ ${ }^{1}$ Education Administration Department, The College of Sakhnin—Academic College for Teacher Education, Sakhnin City, North- \\ ern District, Israel. \\ ${ }^{2}$ Special Education Department, The College of Sakhnin—Academic College for Teacher Education, Sakhnin City, Northern Dis- \\ trict, Israel. \\ ${ }^{3}$ Educational Counselling Department, The College of Sakhnin-Academic College for Teacher Education,Sakhnin City, Northern \\ District, Israel.
}

How to cite this paper: Waleed Dallasheh, Ihab Zubeidat, Sehrab Masri. (2021). Emotional Intelligence, Learning Motivation and Inclusion Ability among Arab Minority Special Education Teachers in Israel. The Educational Review, USA, 5(9), 343-354.

DOI: 10.26855/er.2021.09.004

Received: July 24, 2021

Accepted: August 22, 2021

Published: September 27, 2021

Corresponding author: Ihab Zubeidat, Special Education Department, The College of Sakhnin-Academic College for Teacher Education, Sakhnin City, Northern District, Israel.

Email: izubeidat@hotmail.com

\begin{abstract}
This study examined the relationship between special education teachers' emotional intelligence and the learning motivation of students with specific learning disorders, moderated by the teachers' inclusion ability in regular education in Arab minority in Israel. The research setup is quantitative-correlative. The sample included 406 special education teachers (128 male and 278 female) in elementary and middle schools. The participants were asked to answer the following self-report questionnaires: sociodemographic background data, emotional intelligence, learning motivation, and a school inclusion index. The findings indicated significant positive relationships between emotional intelligence, school inclusion ability and learning motivation among the students from the teachers' viewpoint. In addition, the school inclusion variable was a moderator between the teachers' emotional intelligence and the learning motivation of the students with specific learning disabilities. Also, differences were found in the teachers' emotional intelligence and school inclusion ability on the demographic variables: age, gender, role and teaching experience. The necessary conclusion indicated that intelligent use of emotion and inclusion ability predicts the learning motivation among students with specific learning disorders.
\end{abstract}

\section{Keywords}

Emotional Intelligence, School Inclusion, Learning Motivation, Specific Learning Disorders, Arab Minority In Israel

\section{Emotional Intelligence (EI)}

Emotional intelligence (EI) is defined as the capability to perform precise deductions about emotions, and use emotions and emotional knowledge to guide thinking and behavior (Mayer et al., 2008). According to Ben-Zeev (2000), EI has two basic elements: first, recognizing one's own emotions and those of others, and second, guiding one's own emotions and those of others. EI allows an individual to function better, not necessarily due to theoretical knowledge, but by means of various emotional skills (Boyatzis et al., 2017). One's competence to identify one's own emotions and those of others is not just a conscious ability, but an emotional ability that depends largely on sensitivity and being able to identify with the other. Perceiving the other's emotions requires emotional closeness to him or her, so that EI is not just 
intelligence, but both intelligence and emotion (Ben-Zeev, 2000; Dolev \& Leshem, 2016; Hen \& Sharabi-Nov, 2015).

In the realm of education, EI is a collection of emotional, personal and social capabilities, which affect one's ability to cope effectively with the demands of the environment, and includes a number of areas: intrapersonal and interpersonal competences, coping with stressful situations, adaptability, and general mood (Danielle, 2019). In this context, it was found that EI contributes to scholastic achievements in high school and college, and to the success of prevention programs among adolescents and young adults, better decision making, and improved performance at work (Boyatzis et al., 2017; Goleman, 1998).

EI is especially important for teachers. Teaching is described as one of the professions that require particularly high levels of EI. The relationship between EI and high-quality teaching relies largely on the fact that the teaching profession is an emotional profession, largely based on interpersonal interactions, and on caring and concern (Slaten et al., 2015). In their work, teachers experience a wide and intensive array of emotions. These emotions affect teachers' wellbeing, their functioning, levels of motivation, relationship with their students, and how they perform their job. These characteristics, in turn, affect the students' academic achievements and personal wellbeing. Teachers who are aware of their emotions can manage the classroom and the students, react appropriately, make effective decisions, maintain high learning motivation, and understand the students' emotions (Dolev \& Leshem, 2016; Durdu \& Shahin, 2018; Greenberg, 2009; Masri, 2014). On the other hand, not understanding students' emotions leads teachers to misinterpret the students' learning, which can essentially disrupt their learning process.

Even more so, teaching in special education encompasses emotional involvement, which presents teachers with meaningful emotional experiences that arise from ongoing interactions with special needs students. These interactions require a high degree of devotion and emotional involvement, which is not typical of other professions. The teachers' ability to cope with the students' emotions and their own is a significant element and emotional challenge in their work (Mendelson, 2016). It was also found that emotional involvement is a major factor in the burnout of teachers who work with children with severe behavior disorders of specific learning disabilities. Emotions such as compassion, frustration and guilt are a big challenge in the educational work, and are manifested in the teachers' capability to cope with their own and their students' emotions, and their ability to respond to their emotional needs (Mendelson, 2016).

\section{Inclusion in Regular Education}

The prevalent approach today in the Israeli Ministry of Education is to encourage inclusion and integration of special education students with specific learning disorders in regular education frameworks, which necessitates educational processes that are adapted to this population through educational and therapeutic diagnosis and intervention processes. These processes are performed by the regular school staff, with the aid of a psychologist or educational consultant, a teacher who has specialized in specific learning disorders, and when necessary-other para-medical professionals and regional supervisors (Shimoni \& Gavish, 2017; Tal, 2017).

Educational systems throughout the world are experiencing changes, which create many challenges, especially in the context of providing equal educational rights to children from varied backgrounds and with special educational needs. Therefore, general educational frameworks have been providing services for children with specific learning disorders and other disorders. Including these students in general schools has affected United Nations declarations and conferences; namely that these frameworks should make available full participation of all students in their general education classes, and that they should be given the right to quality education on an equal basis with their peers (Leyser et al., 2011). The aim of including children with specific learning disorders and other disorders in regular schools is to break the barriers between regular and special education, and give these students the feeling that they are no different than other children in the community (Dev \& Kumar, 2015). Consequently, teachers must have skills that help them to teach special needs students in regular schools.

Inclusive education allows special needs students to attend regular classes with regular teachers. This process provides an equal response to all the students, and enables interaction with students from regular education. The development of 'inclusive special education' was meant to provide a vision and guidelines for education policy, procedures and strategies to provide all students - including those with special needs - with effective education (Hornby, 2015). One implication is to fix and rebuild the school and its facilities, so that all the students can participate in all the social and educational opportunities that it has to offer. This verifies education as a basic human right in a socially-just society (Hofman \& Kilimo, 2014). Therefore, policymakers, principals and educators must invest more time in inclusion classrooms, and investigate teaching methods and strategies that achieve positive results (Irwin \& Baker, 2012). In this context, a semantic confusion between the terms segregation, normalization, integration and inclusion has prompted scholars to try and recreate the original meaning of these concepts (Rodriguez \& Garro-Gil, 2015; Shai, 2011).

The teacher has a crucial role in creating optimal inclusion in regular education. Mor and Luria (2011) emphasized 
the personal and personality features of the teacher's role, and described the educator as a positive and stable emotional anchor for the student. Therefore, the teacher must have a well-formed perception, emotional efficacy and communications skills. Silberstein and Katz (1998) especially noted the trait of caring, which incorporates various aspects of the relationship that is formed between the teacher and his or her students. Razar and colleagues (2011) argued that empathetic teachers were found to have a strong moral fiber, to relate emotionally and mentally to their students, and to serve as a moral model for students and colleagues alike. These personal interactions contribute to higher quality teaching and learning, and improve students' behavior. Empathetic teachers reinforce the students' sense of belonging to the school, and their relationship to teachers and peers (Glicko \& Braun-Levinson, 2016).

\section{Learning Motivation}

Motivation to learn is an important component of the learning process. Recognition of the central role played by motivational processes in learners' success has been increasing in recent decades (Kim \& Cho, 2014; Roness \& Smith, 2010; Xu, 2013). A number of studies (Ersoz, 2016; Hartnett et al., 2011; Roness, 2011) have examined the relationship between students' learning motivation and their social goals, using a dichotomous distinction between "approach orientation"-by which the student aspires and acts to achieve positive results—and 'avoidance orientation' - by which the student tries to avoid obtaining negative results (Elliot \& McGregor, 2001). This distinction serves to predict the learning capability, involvement in learning, social anxieties, and the learning motivation of adolescent students (Conroy \& Elliot, 2004; Ersoz, 2016; Lipton et al., 2016).

Typically, the performance of students with high intrinsic motivation increases with time (Shernoff \& Csikszentmihalyi, 2009). For example, they experience positive emotions when they do their homework (Froiland, 2011), and this, in turn, positively affects their sense of wellbeing (Deci \& Ryan, 2008; Gottfried, 1990). It was found that the higher students' intrinsic motivation was, the less they were likely to drop out of school (Vallerand \& Bissonnette, 1992), and that intrinsic motivation had a very significant effect on schoolchildren's performance and their happiness index (Froiland et al., 2012; Grant, 2008).

\subsection{Specific Learning Disorders: The Situation in Arab Minority in Israel}

'Specific learning disorders' is a general term that relates to a group of heterogenic disorders that manifest in significant difficulties in acquisition of attention, speech, reading, writing, conceptualization, and/or mathematical skills. These learning disorders are linked to a variety of neuropsychological developmental disorders. They are internal, and it is assumed that they stem from a central neurological disfunction, and can appear throughout one's life cycle. Although specific learning disorders can occur simultaneously with other limiting conditions - whether internal (such as sensory impairment, mental retardation, emotional disorder) or external (such as cultural differences, insufficient or inadequate teaching)—it seems that it is not a direct result of these conditions (Margalit, 2000).

Russak et al. (2017) mentioned a number of definitions of specific learning disorders, in an attempt to differentiate people with difficulties from people with this disorder: 1 . A definition that emphasizes the incompatibility between achievements and intelligence; 2. A functional definition based on examining the functioning in a certain area and comparing it to what is expected from someone in the same age group; 3. A definition based on response to therapy, which focuses on the individual's ability to change over time from a preventive point of view.

The Arab population in Israel has exceptionally high rates of students with disabilities- $17.2 \%$ versus $8.7 \%$ in the Jewish population. Arab schools lack the professional knowledge required to identify students with specific learning disorders, and to refer them for diagnosis and treatment, so that it is often the case that these children are identified at a later stage in life, when the capacity to effectively treat their problems is minimal. Also, there is a scarcity of valid and reliable diagnostic tools adjusted to the needs of Arab schools to diagnose specific learning disorders, in addition to a lack of professional, experienced Arabic-speaking manpower, which is detrimental to the ability of existing centers to perform precise and reliable diagnoses. These findings have been known since the establishment of the Margalit Committee to investigate the situation of learning-disabled children (Abu Asbeh \& Avishai, 2008). Another problematic topic pertaining to the identification and treatment of students with specific learning disorders in Arab society is the absence of diagnostic tools in Arabic, developed from a professional view of the diagnostic issues as they are culturally reflected in society (Jabareen \& Agbariya, 2010).

Additionally, there is a paucity of information relating to the number of Arab students with specific learning disorders, a scarcity of trained Arabic-speaking professionals and psychologists with experience in these disorders, too few consulting hours, lack of adequate knowledge among teachers on the topic of learning disorders, and no methodical intervention programs. All of the above have resulted in misguided opinions on the part of Arab teachers and parents concerning the inclusion of children with specific learning disorders in regular classes (Abu Hassin \& Samara, 2007). 


\subsection{Rationale, Aims, Research Questions and Research Model}

Arab minority in Israel is of a traditional-patriarchal nature, and one finds contradicting attitudes of teachers towards students in the regular education system with specific learning disorders (Karni-Weizer \& Reiter, 2012). It is, therefore, important to examine emotional-educational aspects, and especially special education teachers' EI and inclusion capabilities that are linked to these students' learning motivation. Findings could contribute, both in theory and in practice, to understanding the relationships between these variables, as they are manifested among special education teachers and students with specific learning disorders in the Arab education system. The findings could also serve as a basis for adapting teaching strategies to the needs of these student, teacher and principal populations, so that they can improve the students' learning motivation levels and their self-image. Form a theory point of view, this research could augment existing studies of education in the Arab minority in Israel, especially due to its emphasis on the importance of training and exposure of special education teachers to the issue of including students with specific learning disorders, which could optimally support their full integration and equality in regular education.

The few studies that were conducted in this area, some in Arab minority, have indicated a significant positive relationship between positive attitudes towards inclusion, integration, and training in special education. Teachers who had participated in special education training courses developed positive attitudes towards inclusion and integration, implemented them in their day-to-day praxis, reported that the school curriculum could be adjusted, and emphasized that the use of technical aids was feasible. Also, they reported commitment to the successful inclusion and integration of the students_educationally, socially and personally (Al-Haj, 1989; Karni-Weizer \& Reiter, 2012; Odeh, 2007; Reiter \& Bryen, 2010). These findings were corroborated in a recent study by Authors (2019), which showed that special education teachers in Arab minority reported higher degrees of inclusion and empathy than their counterparts in regular education.

Most research on relationships between special education teachers' emotional-educational aspects and the learning motivation of students with specific learning disorders has been conducted in Western societies. There are few such studies in Israel, whether in Jewish or Arab minority. Hence, the aim of this study is to examine the relationship between the EI of special education teachers in Arab minority and the learning motivation of students with specific learning disorders, moderated by the inclusion capabilities of these teachers.

This is undoubtedly a new study in its field, which investigates this issue in Arab minority in the north of Israel. This investigation can shed light on the difference between the perceptions of special education and regular education teachers, following which appropriate intervention programs can be formulated in order to increase the awareness of both types of teachers to the importance of nurturing emotional-educational aspects such as emotional intelligence and inclusion of special education children in the regular education system. Consequently, the main research questions are:

A. Is there a relationship between emotional intelligence and the learning motivation of students with specific learning disorders moderated by inclusion abilities from the perspective of special education teachers in Arab minority?

B. Do demographic data (particularly age, gender, role and years of teaching experience) distinguish between special education teachers in Arab minority on inclusion and emotional intelligence?

Figure 1 depicts the links between this study's variables according to the theoretic background.

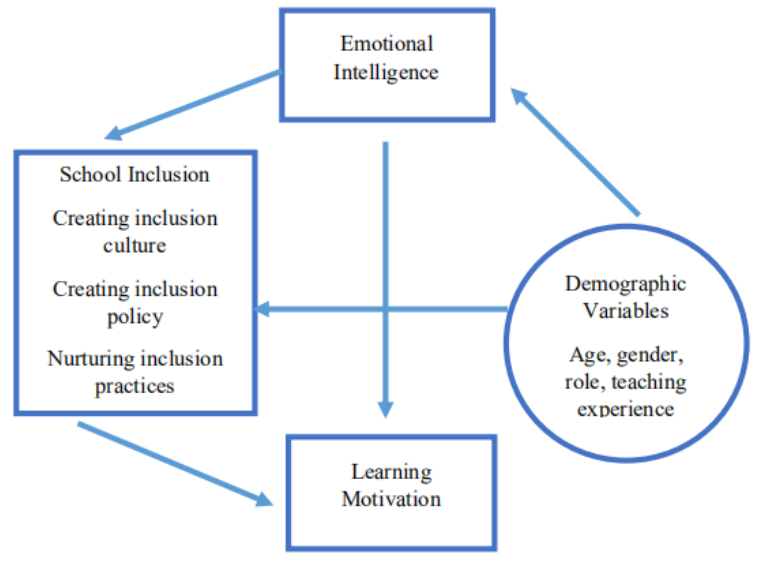

Figure 1. Research model. 
Based on the above, the following hypotheses were formulated:

H1: A significant positive relationship will be found between the teachers' EI and school inclusion capabilities, and the students' learning motivation.

H2: The school inclusion capability will moderate the relationship between the teachers' EI and the students' learning motivation.

H3: Differences in EI and school inclusion capability will be found according to demographic variables: gender, age, role, and years of teaching experience.

\section{Method}

\subsection{Participants}

The research population included all the elementary and middle school teachers employed in the Arab minority in the north of Israel. The sample included 406 special education teachers (128 male and 278 female). The sampling method was a convenience sample, in order to ensure an equal opportunity for all the teachers to take part in the present study. In a convenience sample, the researchers choose the sampling units that are available to them, meaning the sample of this study, but there are limitations relating to the representativeness of this kind of sample (Cohen \& Arieli, 2013). Table 1 presents the demographic characteristics of the participants.

Table 1. Sociodemographic characteristics of participants $(\mathrm{N}=406)$

\begin{tabular}{cccc}
\hline Variable & Options & Frequency & Percentage \\
\hline \multirow{2}{*}{ Gender } & Male & 128 & $26 \%$ \\
& Female & 278 & $74 \%$ \\
Age & $21-30$ & 59 & $14.5 \%$ \\
& $31-40$ & 148 & $36.5 \%$ \\
Education & $41-50$ & 126 & $31 \%$ \\
& Over 50 & 73 & $18 \%$ \\
Teaching experience & Senior teacher & 25 & $6 \%$ \\
& BA & 284 & $70 \%$ \\
Role at school & MA and above & 97 & $24 \%$ \\
& Up to 5 years & 85 & $21 \%$ \\
Age group & 6 -10 years & 118 & $29 \&$ \\
& 11 years and more & 203 & $50 \%$ \\
Type of school & Teacher & 280 & $69 \%$ \\
& Other role (homeroom educator, coordinator, vice principal) & 126 & $31 \%$ \\
Classes & Elementary school & 271 & $67 \%$ \\
& Middle school & 135 & $33 \%$ \\
\hline
\end{tabular}

\subsection{Tools}

The respondents answered the following questionnaires:

1) Sociodemographic Questionnaire. Gender, age, education, teaching experience, role at school, age group, 
type of school and type of class.

2) The Schutte Self Report Emotional Intelligence Test (SSEIT) (Schutte et al., 1998). 33 statements on a Likert scale of 1 (strongly disagree) to 5 (strongly agree), based on the model of emotional intelligence developed by Salovey and Mayer (1990). 15 items (3, 4, 5, 7, 10, 11, 17, 20, 25, 26, 28, 29, 30, 32, 33) measure emotions $(\mathrm{V}), 9$ items $(2,6,12,13,19,21,22,27,31)$ measure organization of emotions $(\mathrm{X})$, and 9 items $(1,8,9$, $14,15,16,18,23,24)$ measure use of emotions (U). The original internal reliability coefficient of the EI questionnaire is $\alpha=0.96$.

3) Inclusion Index (Ainscow et al., 2004). 35 statements that examine three dimensions of inclusion: a. Creating inclusion culture, 13 statements (i.e., There is mutual respect between the staff members and the students); b. Creating inclusion policy, 11 statements (i.e., The school accepts students from all over the area); c. Nurturing inclusion practices, 11 statements (i.e., All of the students are encouraged to participate in lessons). The replies are given on a 4-point Likert scale: ' 1 ' expresses lack of knowledge about inclusion, and indicates an absence of this capability; ' 2 ' expresses that the respondent disagrees with the statement, and indicates an absence of this capability; ' 3 ' expresses medium agreement, and indicates medium inclusion; and ' 4 ' expresses full agreement, and indicates high inclusion capability. The internal reliability coefficient of the general questionnaire is $\alpha=0.93$.

4) Motivated Strategies for Learning Questionnaire (MSLQ) (Pintrich et al., 1987). 15 statements on a 7-point Likert scale from 1 (completely untrue for me) to 7 (very true for me). Example statements: "I am very interested in the content domains studied in this faculty" or "It is very important to me to understand the materials studied in the courses in this faculty". The questionnaire originally examined students' learning motivations and learning strategies in a specific university faculty. The questionnaire examines three measures: intrinsic direction to apply learning strategies, task value, and critical thinking. The internal reliability coefficient of the MSLQ questionnaire is $\alpha=0.88$.

\subsection{Procedure}

The researchers approached principals of elementary and middle schools in Arab minority in the north of Israel, and explained the rationale and aims of the study. After receiving the formal authorization, the researchers met the teachers at random in the school staff room, explained about the study and its framework, and asked them to be part of the sample. Teachers who consented were given the questionnaires, and were asked to fill them out and return them within two weeks to the school secretary's office. The questionnaires were subsequently collected, and the answers were entered into SPSS software, to be analyzed at a later stage.

\subsection{Results}

The first hypothesis assumed that a significant positive relationship would be found between the teachers' EI and school inclusion capabilities, and the students' learning motivation. That is to say, a significant positive relationship would be found between the teachers' EI and their students' learning motivation, and a significant positive relationship would be found between the teachers' inclusion capabilities and their students' learning motivation. To examine this hypothesis, Pearson correlation coefficients between the variables were calculated. The results are presented in Table 2. Positive significant relationships were found between EI and general school inclusion $(\mathrm{r}=0.41)$, creating inclusion culture $(\mathrm{r}=0.39)$, and nurturing inclusion practice $(\mathrm{r}=0.45)$. The relationship between EI and creating inclusion policy was non-significant. Furthermore, a significant medium positive relationship was found between EI and students' learning motivation ( $\mathrm{r}=0.49)$. Hypothesis H1 was corroborated.

Table 2. Pearson correlations between EI, school inclusion and learning motivation $(\mathrm{N}=406)$

\begin{tabular}{|c|c|c|c|c|c|}
\hline \multirow[b]{2}{*}{ Variable } & \multicolumn{4}{|c|}{ School inclusion capability } & \multirow[b]{2}{*}{$\begin{array}{l}\text { Learning motiva- } \\
\text { tion }\end{array}$} \\
\hline & General & $\begin{array}{c}\text { Creating inclusion } \\
\text { culture }\end{array}$ & $\begin{array}{l}\text { Creating inclusion } \\
\text { policy }\end{array}$ & $\begin{array}{l}\text { Nurturing inclusion } \\
\text { practices }\end{array}$ & \\
\hline $\begin{array}{l}\text { Emotional intelli- } \\
\text { gence }\end{array}$ & $0.41^{*}$ & $0.39 *$ & 0.56 & $0.45^{*}$ & $0.49 *$ \\
\hline $\begin{array}{l}\text { Learning motiva- } \\
\text { tion }\end{array}$ & $0.48^{*}$ & $0.42 *$ & $0.49 *$ & 0.51 & --- \\
\hline
\end{tabular}

$* \mathrm{p}<0.05$ 
The second hypothesis expected that the school inclusion capability would moderate the relationship between the teachers' EI and the students' learning motivation. Linear regression in blocks was performed to examine this hypothesis. The results are described in Table 3 . The findings indicated that the regression analysis of one independent variable (EI) found a correlation between EI and learning motivation $(\beta=0.44 ; p=0.047)$. On the other hand, in a multivariable regression, the contribution of EI was non-significant $(\beta=0.38 ; \mathrm{p}=0.55)$, whereas the contribution of school inclusion capability was significant $(\beta=0.29 ; \mathrm{p}=0.01)$. Hence, $\mathrm{H} 2$ was confirmed.

Table 3. Linear regression for $\mathrm{EI}$, school inclusion and learning motivation $(\mathrm{N}=406)$

\begin{tabular}{ccccc}
\hline Variable & $\mathrm{B}$ & $\mathrm{B}$ & $\mathrm{t}$ & Significance \\
\hline Constant & 4.83 & - & 5.745 & $>0.01$ \\
Emotional intelligence & 0.07 & 0.38 & 1.54 & 0.03 \\
School inclusion capability & 0.178 & 0.29 & 2.68 & 0.01 \\
\hline
\end{tabular}

The third hypothesis assumed that differences in EI and school inclusion capability would be found according to the demographic variables: gender, age, role, and years of teaching experience. This hypothesis was examined in four steps.

1) Differences in EI and school inclusion capability by gender: A t-test for independent samples was conducted. The results are presented in Table 4, and indicate significant differences between male and female teachers on EI [t(104)=-3.69; $\mathrm{p}<0.01]$ and inclusion capability [t(104)=-2.43; $<<0.01]$. That is to say, male special education teachers reported lower levels of EI and inclusion capabilities that female teachers did.

Table 4. Comparison between male and female teachers on EI and school inclusion $(\mathrm{N}=406)$

\begin{tabular}{cccccc}
\hline Variable & Gender & $\mathrm{N}$ & Mean & SD & t \\
\hline Emotional intelli- & Male & 128 & 3.15 & 0.79 & $-3.69^{*}$ \\
gence & Female & 278 & 3.92 & 0.92 & 0.68 \\
School inclusion & Male & 128 & 2.11 & 0.75 & $-2.43^{*}$ \\
capability & Female & 278 & 2.56 & 0.75 \\
\hline
\end{tabular}

$* \mathrm{p}<0.05$

2) Differences in EI and school inclusion capability by age: One-way analysis of variance (ANOVA) was performed to examine differences in EI and school inclusion capability between the various age groups of the teachers. The results are shown in Table 5, and confirm the differences as follows:

a. A significant difference in EI was found between teachers in the 21-30 age group and teachers in the 41-50 age group.

b. A significant difference in EI was found between teachers in the 21-30 age group and teachers in the over 50 age group.

Scheffe's post-hoc test indicated significant differences in three comparisons on school inclusion capability:

a. A significant difference in inclusion capability was found between teachers in the 21-30 age group and teachers in the 41-50 age group.

b. A significant difference in inclusion capability was found between teachers in the 21-30 age group and teachers in the over 50 age group.

c. A significant difference in inclusion capability was found between teachers in the 31-40 age group and teachers in the over 50 age group

Table 5. Comparison between teachers by age on $\mathrm{EI}$ and school inclusion $(\mathrm{N}=406)$

\begin{tabular}{|c|c|c|c|c|c|}
\hline Variable & Age group & $\mathrm{N}$ & Mean & SD & $\mathrm{F}$ \\
\hline \multirow{3}{*}{$\begin{array}{l}\text { Emotional intelli- } \\
\text { gence }\end{array}$} & $21-30$ & 59 & 3.82 & 0.72 & \multirow{4}{*}{$2.43^{*}$} \\
\hline & $31-40$ & 148 & 3.79 & 0.81 & \\
\hline & $41-50$ & 126 & 3.53 & 0.92 & \\
\hline \multirow{5}{*}{$\begin{array}{l}\text { School inclusion } \\
\text { capability }\end{array}$} & Over 50 & 73 & 3.42 & 0.82 & \\
\hline & $21-30$ & 59 & 2.67 & 0.74 & \multirow{4}{*}{$1.85^{*}$} \\
\hline & $31-40$ & 148 & 2.61 & 0.79 & \\
\hline & $41-50$ & 126 & 2.42 & 1.76 & \\
\hline & Over 50 & 73 & 2.35 & 0.61 & \\
\hline
\end{tabular}

${ }^{*} \mathrm{p}<0.05$ 
3) Differences in EI and school inclusion capability by role: A t-test for independent samples was conducted. The results are presented in Table 6, and indicate significant differences between participants who were only teachers and others who held various other roles at school on EI [t(104)=-2.47; $<<0.01]$ and inclusion $[t(104)=-1.26 ; p<0.01]$; namely, regular teachers reported lower levels of EI and inclusion that teachers that held other roles at school did.

Table 6. Comparison between teachers by role on EI and school inclusion $(\mathrm{N}=406)$

\begin{tabular}{cccccc}
\hline Variable & Gender & $\mathrm{N}$ & Mean & SD & t \\
\hline Emotional intelli- & Teacher & 280 & 3.64 & 0.88 & 0.81 \\
gence & Other role & 126 & 3.95 & $2.47^{*}$ \\
School inclusion & Teacher & 280 & 2.47 & 0.76 & $-1.26^{*}$ \\
$\quad$ capability & Other role & 126 & 2.86 & 0.65 & \\
\hline${ }^{*} \mathrm{p}<0.05$ & & &
\end{tabular}

4) Differences in EI and school inclusion capability by years of teaching experience: One-way analysis of variance (ANOVA) was performed to examine differences in EI and school inclusion capability between the various groups of teachers' teaching experience. The results are shown in Table 7, and confirm the following differences:

a. A significant difference in EI was found between teachers with up to 5 years of experience and teachers with 6-10 years of experience.

b. A significant difference in EI was found between teachers with up to 5 years of experience and teachers with 11 and more years of experience.

For school inclusion capability, the findings indicated significant differences in only one comparison—between teachers with up to 5 years of experience and teachers with 11 and more years of experience.

Table 7. Comparison between teachers by years of teaching experience on $\mathrm{EI}$ and school inclusion $(\mathrm{N}=406)$

\begin{tabular}{cccccc}
\hline Variable & Years of teaching experience & $\mathrm{N}$ & Mean & SD & F \\
\hline \multirow{2}{*}{$\begin{array}{c}\text { Emotional intelli- } \\
\text { gence }\end{array}$} & Up to 5 years & 85 & 3.89 & 0.65 & $3.64^{*}$ \\
& 6-10 years & 118 & 3.71 & 0.82 & 0.90 \\
& 11 years and more & 203 & 3.65 & 2.68 & 0.84 \\
School inclusion & & 85 & 2.57 & 0.74 & $2.93^{*}$ \\
capability & & 118 & 2.51 & 0.73 \\
\hline
\end{tabular}

${ }^{*} \mathrm{p}<0.05$

\section{Discussion}

The main goal of this study was to examine the relationship between emotional intelligence (EI) and the learning motivation of students with specific learning disorders, moderated by the special education teachers' inclusion ability, in the Arab education system in the north of Israel. The central research question was: Is there a relationship between emotional intelligence and learning motivation of students with specific learning disorders moderated by the inclusion ability from the perspective of special education teachers in Arab minority? The study examined three hypotheses, which are discussed in this section.

The findings that related to the first hypothesis, which assumed that a significant positive relationship would be found between the teachers' EI and school inclusion capabilities and the students' learning motivation, indicated significant positive relationships between EI and inclusion, as well as a significant positive relationship between teachers' EI and students' learning motivation. The significant relationship between EI and school inclusion has been investigated widely, and similar findings have been found; i.e., the teacher's EI is central to creating inclusion in the classroom. In other words, a teacher's personal and personality aspects are very important to educational work. Hence, in a classroom that integrates students with specific learning disorders, the teacher must be aware of these students' needs and emotions, and be able to teach and promote them with these needs in mind within the framework of the regular curriculum or sub- 
ject that is being taught (Mor \& Luria, 2011).

A teacher with EI is an inclusive teacher, who relates the entirety of the students' difficulties and needs, not just to their learning difficulties. This teacher knows the students' capabilities, and allows them to realize their potential (Danielle, 2019; Sulemani, 2006), and gets to know the students and their circumstances, strengths and weaknesses well, along with their educational, social and emotional situation. This knowledge enables objective analysis of the reasons for failure and of the progress process, and thus leads to realistic targets and working towards them (Dolev \& Itzkovitz; 2016; Razar, 2013). An inclusive teacher reveals a high degree of emotional intelligence towards his/her students, so the relationship between EI and good teaching relies largely on the fact that teaching is an emotional profession, based mostly on interpersonal relationships (Boyatzis et al., 2017; Brackett \& Katulak, 2006).

It should be noted that EI is one of the foundations of good, intelligent teaching. Teaching methods are not enough; the teacher must have EI in order to include all the children and all their shades and features, especially children with specific learning disorders. With special needs children, the importance of the teacher's role in the learning process is intensified, because in this case the teacher has to exhibit more EI and inclusion, and know how to cope with the variety and diversity among the students - educational as well as emotional and social. Furthermore, this finding shows that despite the difficulties of the Arab education system such as inadequate funding and physical resources, the Arab education system (especially the teachers) function well as expected despite the problems.

The findings that related to the second hypothesis, which assumed that the school inclusion capability would moderate the relationship between the teachers' EI and the students' learning motivation, showed that school inclusion was indeed a moderating variable between the two other variables. Students with specific learning disorders fell misunderstood at school, have no one to share their feelings with or to hear them. The teachers' role is to create for these students a space in which they feel secure, where they can share the social fears that may accompany their loneliness, and encounter understanding, recognition of their feelings, and faith in their abilities (Aploig \& Shalev-Vigiser, 2010; Dolev \& Itzkovitz, 2016). In such situations, teachers' EI can significantly improve these students' emotional, social and learning products, and increase their intrinsic learning motivation (Rodriguez \& Garro-Gil, 2015; Roffey, 2012).

The teacher's EI can affect the students and motivate them, especially if the teacher has goo inclusion capabilities for students with specific learning disorders (Dolev \& Leshem, 2016; Hargreaves, 2001). In other words, the teacher's EI affects his/her relationship with the students, teaching mode and class management, which directly and indirectly affect the students' efficacy and learning motivation. This is even more so for students with specific learning disorders, which necessitate constant inclusion in order to enter their world (Hargreaves, 2001; Nias, 2006). The teacher's EI moderated by school inclusion capability is the way to motivate students, especially special needs students, so that their combination can change the child's behavior and emotional world, increase learning motivation, and improve achievements (Brackett et al., 2009; Jennings \& Greenberg, 2009; Roffey, 2012).

Meaningful school inclusion ability means knowing the other in every sense of the word, which doubles the teacher's power to know the students, understand their emotions, and realize what bothers them and what they fear. EI moderated by school inclusion capability guarantees the teacher's warmth and love to the special-needs students, and the teacher can thus influence the students in general, and especially their learning motivation, which improves learning achievements. In the context of teachers in the Arab education system, it is evident that the Arab teacher is gifted with good school inclusion abilities, which help the teachers and students alike. The authors believe that the degree of the Arab teacher's school inclusion abilities is directly linked to the Arab culture, which is characterized by inclusion of the other, which is manifested in support to others, compassion social collectivity, and so on.

The findings that related to the third hypothesis, which assumed that differences in EI and school inclusion capability would be found according to the demographic variables: gender, age, role, and years of teaching experience, corroborated the hypothesis. Significant differences were found between male and female teachers in EI and school inclusion capability. Differences in EI and school inclusion capability were also found between younger and older teachers, teachers with different roles at school, and years of teaching experience.

In this context, Holander and Celikel-Esser (2007) found that EI levels were higher among women than among men. Mayer and colleagues (2008) also found gender differences in the level of EI, so that women scored higher on EI than men did. In a more recent study, Gavish (2017) found that the school inclusion ability of female teachers was higher than that of men. Furthermore, Mayer and colleagues (2008) found that the age variable affected teachers' EI levels, so that the older the teacher was, the higher his/her emotional intelligence was. This finding is contradicted by the findings of the present study, which found higher EI among the younger teachers. It seems reasonable that teachers' reaching experience is related to their age. Gavish (2017) indicated that special education teachers were more inclusive that regular education teachers. Special education teachers see their work as a mission, and inclusion as an ethical, social, and systemic issue, and they are the ones who work in a space that requires the practice of inclusion. Therefore, the first step 
in EI is to identify and understand emotions, and the second step is to implement inclusion (Gavish, 2017).

\section{Conclusions}

In light of the present study's findings, a number of conclusions can be generalized to the population of Arab special education teachers. A key conclusion is that since use of emotions and inclusion by teachers predicts learning motivation among students with specific learning disorders, it is befitting that the education system, and particularly policymakers and decision-makers, pay more attention to the array of possible interventions to improve the level of teachers' use of emotions and school inclusion. In our digitized era, an increased use of computerized learning aids is evident. This absurd situation might make the use of emotions and school inclusion somewhat minor or worthless in the teachers' teaching processes, because many in the education system believe that the integration of technology and computerization into the school system is the one and only way to achieve meaningful learning. This puts the 'computer' in the center, rather than the student or the teacher, which could explain the unsatisfactory learning results among students in general, and students with specific learning disorders in particular.

The present study has found that female teachers have a greater effect on children with learning disorders than male teachers do. This should be considered when building the school timetable, so that more female teachers work in inclusive classrooms. In addition, special education teachers were found to have a greater effect on students with specific learning disorders than regular teachers, due to their higher levels of EI and school inclusion capabilities. The significance is that teachers trained in special education should teach in inclusive classrooms. Furthermore, younger teacher with less years of teaching experience seem to have a greater effect than their older counterparts; it is, thus, recommended that younger teachers are allocated to inclusive classrooms, in order to achieve better and more meaningful learning.

\section{References}

Abu Asbeh, K. and Avishai, L. (2008). Recommendations to improve the Arab education system in Israel. Jerusalem: Van Leer Institute. [Hebrew]

Abu Hassin, J. and Samara, N. (2007). General education and special education teachers' attitudes to integration of children with learning disorders in regular education in the Arab education system in Israel. Baqa al-Gharbiyye: Al-Qasemi College of Education. [Hebrew]

Ainscow, M., Booth, T., and Dyson, A. (2004). Understanding and developing inclusive practices in schools: A collaborative action research network. International Journal of Inclusive Education, 8(2), 125-139.

Al-Haj, M. (1989). Social research on family life style among Arabs in Israel. Journal of Comparative Family Studies, 20, $175-194$.

Aploig, N. and Shalev-Vigiser, Y. (2010). The teacher's role in the $21^{\text {st }}$ century. Position paper, Van Leer Education Conference. Jerusalem: Van Leer Institute. [Hebrew]

Authors. (2019). Inclusion, self-efficacy, and empathy toward students with specific learning disorders. BeMa’aglei Hinuch, 8, 1-17. [Hebrew]

Ben-Zeev, A. (2000). Emotional intelligence: The conceptual aspect. Nefesh, 4, 47-54. [Hebrew]

Boyatzis, R., Stubbs, E., and Taylor, S. (2017). Learning Cognitive and Emotional Intelligence Competencies through Graduate Management Education. Academy of Management Learning \& Education, 1(2), 150-162.

Brackett, M. A. and Katulak, N. A. (2006). Emotional intelligence in the classroom: A skill-based training for teachers and students. In J. Ciarrochi and J. D Mayer (Eds.), Improving emotional intelligence: A Practitioner's Guide (pp. 1-27). New York, NY: Psychology Press.

Brackett, M. A., Patti, J., Stern, R., Rivers, S. E., Elbertson, N. A., Chisholm, C., and Salovey, P. (2009). A sustainable, skill-based approach to building emotionally literate schools. In M. Hughes, H. L. Thompson \& J. B. Terrell (Eds.), Handbook for developing emotional and social intelligence: Best practices, case studies, and strategies (pp. 329-358). San Francisco, CA: Pfeiffer.

Cohen, N. and Arieli, T. (2013). A conflict environment as a research field: Challenges and snowball sampling. Politics, $22,2-26$. [Hebrew]

Conroy, D. E. and Elliot, A. J. (2004). Fear of failure and achievement goals in sport: Addressing the issue of the chicken and the egg. Anxiety, Stress, and Coping, 17(3), 271-285.

Danielle, E. K. (2019). Emotional Intelligence in Instructional Design and Education. California School of Education, Alliant International University, San Francisco, United States of America. Scientific Research, 10(2), 132-139.

Deci, E. L. and Ryan, R. (2008). Facilitating optimal motivation and psychological well-being across life's domains. Canadian Psy- 
chology, 49(1), 14-23.

Dev, S. and Kumar, J. (2015). Indonesia Teacher's Perception towards Integration of Learning-Disabled Students into Regular Class Room-A study in Dubai \& Abu Dhabi Schools. 2nd Global Conference on Business and Social Science. Procedia-Social and Behavioral Sciences, 211, 605-611.

Dolev, N. and Itkovitz, Y. (2016). Selecting teaching workers, emotional intelligence, and what's in between. Bimat Diyun-Mofet Institute Journal, 58, 38-43. [Hebrew]

Dolev, N. and Leshem, S. (2016). Developing Emotional Intelligence Competence among Teachers. Teacher Development, 21, 23-39.

Elliot, A. J. and McGregor, H. A. (2001). A 2×2 achievement goal framework. Journal of Personality and Social Psychology, 80, 501-519.

Ersoz, G. (2016). An examination of motivational regulations, dispositional flow and social physique anxiety among college students for exercise: A self-determination theory approach. College Student Journal, 50(2), 159-170.

Froiland, J. M. (2011). Parental autonomy support and student learning goals: A preliminary examination of an intrinsic motivation intervention. Child and Youth Care Forum, 40(2), 135-149.

Froiland, J. M., Smith, L., and Peterson, A. (2012). How children can be happier and more intrinsically motivated while receiving their compulsory education. In A. Columbus (Ed.), Advances in psychology research (Vol. 87, pp. 85-112). Hauppauge, NY: Nova Science.

Gavish, B. (2017). Four profiles of inclusive supportive teachers: Perceptions of their status and role in implementing inclusion of students with special needs in general classrooms. Teaching and Teacher Education, 61, 37-46.

Glicko, A. and Braun-Levinson, A. (2016). Coping strategies and patterns of teacher with included children in the state, state-religious and orthodox education systems. In N. Wittenberg (Ed.), From separation to integration: Aspects of child and at-risk youth education (Pamphlet 19, pp. 203-229). Ministry of Education. [Hebrew]

Goleman, D. (1998). Working with Emotional Intelligence. New York, NY: Bantam Books.

Gottfried, A. E. (1990). Academic intrinsic motivation in young elementary school children. Journal of Educational Psychology, 82, 525-538.

Grant, A. M. (2008). The significance of task significance: Job performance effects, relational mechanisms, and boundary conditions. Journal of Applied Psychology, 93, 108-124.

Hargreaves, A. (2001). Emotional geographies of teaching. The Teachers College Record, 103(6), 1056-1080.

Hartnett, M., George, S. A., and Dron, J. (2011). Examining motivation in online instance learning environments: Complex, multifaceted, and situation-dependent. International Review of Research in Open and Distance Learning, 12(6).

Hen, M., \& Sharabi-Nov, A. (2015). The Emotional Educator-A Model to Enhance Teachers Emotional Competence. Research Gate. https://doi.org/Users/Eyal/Downloads/emotionaleducatorinhebrew.pdf.

Hofman, R. H. and Kilimo, J. S. (2014). Teachers' Attitudes and Self-Efficacy Towards Inclusion of Pupils with Disabilities in Tanzanian Schools. Journal of Education and Training, 1, 178-193.

Hollanders, H. and Celikel-Esser, F. (2007). Measuring innovation efficiency INNO Metrics 2007 report. Brussels: European Commission, DG Enterprise.

Hornby, G. (2015). Inclusive special education: Development of a new theory for the education of children with special educational needs and disabilities. British Journal of Special Education, 42(3), 234-256.

Irwin, J. and I. Baker, I. (2012). Promoting Active Reading Comprehension Strategies: A Resource Book for Teachers. Englewood Cliffs, NJ: Prentice Hall.

Jabareen, Y. and Agbariya, A. (2010). Education on hold: Government policy and civil initiatives to promote Arab education in Israel. Nazareth: Dirasat Center/Haifa: The Arab Minority Rights Clinic. [Hebrew]

Jennings, P. A. and Greenberg, M. T. (2009). The Prosocial Classroom: Teacher Social and Emotional Competence in Relation to Student and Classroom Outcomes. Review of Educational Research, 79(1), 491-525.

Karni-Weizer, N. and Reiter, S. (2010). Teachers' attitudes to including children with disabilities in middle school in the Arab sector in Israel. Issues in Special Education and Inclusion, 25, 35-45. [Hebrew]

Kim, H. and Cho, Y. (2014). Preservice teachers' motivation, sense of teaching efficacy, and expectation of reality shock. Asia-Pacific Journal of Teacher Education, 42(1), 67-81.

Leyser, Y., Zeiger, T., and Romi, S. (2011). Changes in Self-efficacy of Prospective Special and General Education Teachers: Implication for inclusive education. International Journal of Disability, Development and Education, 58, 241-255.

Lipton, M., Weeks, J., Daruwala, S., and De Los Reyes, A. (2016). Profiles of Social Anxiety and Impulsivity Among College Students: A Close Examination of Profile Differences in Externalizing Behavior. Journal of Psychopathology \& Behavioral As- 
sessment, 38(3), 465-475.

Margalit, M. (2000). Learning disorders in the classroom: Educational dilemmas in a new reality. Tel Aviv: Mofet Institute. [Hebrew]

Mayer, J. D., Roberts, R. D., and Barsade, S. G. (2008). Human Abilities: Emotional Intelligence. The Annual Review of Psychology, 59, 507-536.

Mendelson, N. (2016). Emotional aspects in the context of the 'compassion fatigue' in the work of teachers with at-risk children in therapeutic boarding school. In N. Wittenberg (Ed.), From separation to integration: Aspects of child and at-risk youth education (Pamphlet 19, pp. 21-47). Ministry of Education. [Hebrew]

Mor, F. and Luria, A. (2011). The role of school in the recovery of students in trouble situations, crisis and trauma. In Y. Siman-Tov \& S. Hen-Gal (Eds.), To grow from crisis (pp. 53-71). Ministry of Education. [Hebrew]

Nias, J. (2006). Thinking about feeling: The emotions in teaching. Cambridge Journal of Education, 26(3), 293-306.

Odeh, M. (2007). Pathogenesis of hepatic encephalopathy: The tumor necrosis factor-alpha theory. European Journal of Clinical Investigation, 37(4), 291-304.

Pintrich, P. R., Smith, D. A. F., Garcia, T., and McKeachie, W. J. (1991). A manual for the use of the Motivated Strategies for Learning Questionnaire (MSLQ). Ann Arbor, MI: National Center for Research to Improve Postsecondary Teaching and Learning.

Razar, M. (2013). The dialog on distress and inclusion: The solution given to the needs of students who work with at-risk children and youth. Encounter of Educational-Social Work, 37, 35-60. [Hebrew]

Razar, M., Warshavsky, B., and Bar Sadeh, A. (2011). A different relationship at school_Forming a different culture in work with at-risk and excluded students. Joint Asalim. [Hebrew]

Reiter, S. and Bryen, N. D. (2010). Attitudinal barriers to rehabilitation. In J. H. Stone \& M. Blouin (Eds.), Available online in: http://doi.org/cirrie.buffalo.edu/encyclopedia/Aarticle.php?id=297 \& language=en.

Rodriguez, C. C. and Garro-Gil, N. (2015). Inclusion and integration on special education. Procedia-Social and Behavioral Sciences, 191, 1323-1327.

Roffey, S. (2012). Teacher wellbeing, pupil wellbeing: Two sides of the same coin. Educational and Child Psychology, 29(4), 8-17.

Roness, D. (2011). Still motivated? The motivation for teaching during the second year in the profession. Teaching and Teacher Education, 27(3), 628-638.

Roness, D. and Smith, S. (2010). Stability in motivation during teacher education. Journal of Education for Teaching, 36, $169-185$.

Salovey, P. and Mayer, J. D. (1990). Emotional intelligence. Imagination, Cognition and Personality, 9, 185-211.

Schutte, N. S., Malouff, J. M., Hall, L. E., Haggerty, D. J., Cooper, J. T., Golden, C. J., and Dornheim, L. (1998). Development and validation of a measure of emotional intelligence. Personality and Individual Differences, 25, 167-177.

Shai, R. (2011). Segregation...normalization...integration...inclusion. Et HaSadeh, 6, 30-34. [Hebrew]

Shernoff, D. J. and Csikszentmihalyi, M. (2009). Flow in schools: Cultivating engaged learners and optimal learning environments. In R. C. Gilman, E. S. Heubner, \& M. J. Furlong (Eds.), Handbook of positive psychology in schools (pp. 131-145). New York: Routledge.

Shimoni, S. and Gavish, B. (2017). Inclusion teachers speak about their place in the integration special needs children in integrated classes. In I. Kupperberg, S. Reiter, \& G. Yitzhak (Eds.), Contemporary issues of integrating special needs children and adults in Israel_Compilation of articles (23-38). Ra'anana: Mofet Institute. [Hebrew]

Silberstein, M. and Katz, P. (1998). A great, expert and professional teacher: Three perspectives of the character of 'Asher the teacher'. Dapim, 26, 53-71. [Hebrew]

Slaten, C. D., Irby, D. J., Tate, K., and Rivera, R. (2015). Towards a Critically Conscious Approach to Social and Emotional Learning in Urban Alternative Education: School Staff Members' Perspectives. Journal for Social Action in Counseling and Psychology, 7(1), 41-62.

Sulemani, R. (2006). They learn anew_Educational intervention program for at-risk students. Jerusalem: Ashalim (joint-Israel). [Hebrew]

Tal, D. (2017). Training for 'inclusive teaching': A three-lane journey. In G. Yitzhak \& S. Siton (Eds.), Writing education: On the link between theory and educational praxis in the teacher training process (pp. 225-248). Pardes Publishing. [Hebrew]

Vallerand, R. J. and Bissonnette, R. (1992). Intrinsic, extrinsic, and motivational styles as predictors of behavior: A prospective study. Journal of Personality, 60(3), 599-620.

$\mathrm{Xu}$, J. (2013). Why do students have difficulties completing homework? The need for homework management. Journal of Education and Training Studies, 1, 98-105. 